\title{
Deafness mutation mining using regular expression based pattern matching Christopher M Frenz
}

Address: Department of Computer Engineering Technology, New York City College of Technology (CUNY), 300 Jay St, Brooklyn, NY 11201, USA Email: Christopher M Frenz - cfrenz@gmail.com

Published: 25 October 2007

BMC Medical Informatics and Decision Making 2007, 7:32 doi:10.1 186/1472-6947-7-32

This article is available from: http://www.biomedcentral.com/1472-6947/7/32

(C) 2007 Frenz; licensee BioMed Central Ltd.

This is an Open Access article distributed under the terms of the Creative Commons Attribution License (http://creativecommons.org/licenses/by/2.0), which permits unrestricted use, distribution, and reproduction in any medium, provided the original work is properly cited.

\begin{abstract}
Background: While keyword based queries of databases such as Pubmed are frequently of great utility, the ability to use regular expressions in place of a keyword can often improve the results output by such databases. Regular expressions can allow for the identification of element types that cannot be readily specified by a single keyword and can allow for different words with similar character sequences to be distinguished.

Results: A Perl based utility was developed to allow the use of regular expressions in Pubmed searches, thereby improving the accuracy of the searches.

Conclusion: This utility was then utilized to create a comprehensive listing of all DFN deafness mutations discussed in Pubmed records containing the keywords "human ear".
\end{abstract}

\section{Background}

Biological research has yielded a vast amount of research data, which can often provide novel insights when the data can be viewed in an aggregated fashion, and thus recent studies have employed computational methods of information extraction from the biomedical literature. These studies have dealt with a wide range of information extractions, including the names of genes and proteins[1], intermolecular relationships [2], and molecular biological descriptors [3].

Pubmed currently catalogs citation and abstract information for over 4,400 biomedical research journals and houses a citation database of over 12.8 million citations[4]. With any database of this size the return of relevant query results is often a difficult task, given the large number of potential matches there likely are for any single query term. These difficulties are compounded even further, given that Pubmed records are all natural language records and searches cannot readily be conducted using a predefined set of terms, as is the case for many relational databases. Thus Pubmed employs a word-matching algorithm, which seeks to match query words to the contents of citation records, and will return all records containing that word in their order of publication starting with the most recent.

For certain types of queries, such as mutations, basic word matching is an ineffective search strategy, since an effective query cannot be specified as a single word, but rather is better expressed as a textual pattern, such as [Residue] [Position] [MutantResidue] [5]. The use of textual pattern matching, however, has a wide array of uses that extend beyond the location of mutations within Pubmed records, and include the ability to distinguish between articles which discuss pKa values as opposed to articles that discuss Protein Kinase A (PKA), which would both be yielded by a Pubmed search for the "pKa" word. These above examples, illustrate the two major applications that text patterns offer to Pubmed searching; 1) the identification 
of elements that cannot be specified by a single word and 2) distinguishing between two different words that are comprised of a similar sequence of characters [6]. Textual patterns are commonly matched via the use of regular expressions and studies that involve the extraction of biochemical mutation data from biomedical literature have demonstrated a high degree of success [5,7]. This study seeks to develop a Perl based utility Perl Regular Expressions for Pubmed (PREP.pl, See Additional File 1, which allows the searching of Pubmed citation records for the presence of textual patterns and for the placement of match containing records into an HTML formatted output file. This Perl based utility will then be utilized to construct a comprehensive listing of DFN mutations discussed in Pubmed records containing the "human ear" keywords.

\section{Implementation \\ The PREP utility}

The script interacts with Pubmed via NCBI's E-Utilities interface [4] and the LWP module handles all HTTP based communication. The script begins by using the ESearch method to query Pubmed for all records containing a user defined search term, such as "lysozyme" or "HIV". Pubmed ID numbers of all matching records are temporarily stored on the Pubmed server and can be accessed using the EFetch method and an assigned Web environment variable and query key, which is returned by the ESearch method. Records returned by the EFetch method are requested in XML format, since the well-defined hierarchical structures of XML documents greatly simplifies parsing tasks [6]. This script makes use of the XML::LibXML Perl module for XML parsing, and from each Pubmed record the title of the article, the journal information, the abstract, and the Pubmed ID of the record, are extracted, based on their corresponding XML tag names.

A user specified regular expression is then used to search the abstract and title fields of each record and look for a textual pattern match. Only the title and abstract fields are searched, since these are the fields in which pattern matches are most likely to be found, and the elimination of other fields reduces the potential for false positives. If a match occurs the journal information, the abstract, and title are output to an HTML file (Figure 1).

The title is output in the format of a hyperlink to the Pubmed record that corresponds to that article, to allow for easy retrieval of any additional information pertaining to the article that the output file does not provide or in certain cases easy retrieval of the entire article. The generation of an HTML output allows for the results to be easily shared among users working on disparate computing platforms. Records that contain no matches to the text pattern of interest are not written to an output file. On an AMD Athlon 2000+ the PREP script can process an average of 500 abstracts per minute.

PREP can be run from the command line of any Linux or Unix machine that has the XML::Lib::XML Perl module installed. The regular expression used within the script is modified by changing the value of the \$regex variable within the script, as indicated by the code documentation. Command line script execution can be initiated using the standard Perl command line syntax of "perl Prep.pl Keywords". The utility was chosen to be implemented in a command line fashion since this makes the utility suitable for easy inclusion in more comprehensive data mining scripts where the search functionality of PREP may provide useful.

\section{Validation of utility}

As a test of the specificity obtainable by the PREP script, all Pubmed records that resulted from a search for the word "lysozyme" were checked for pattern matches to the Protein Kinase A abbreviation "PKA" by using the regular expression PKA within the PREP script. At the time the test was conducted there were 19,964 records returned, and the PREP script indicated that only 3 records contained the textual pattern "PKA". These findings were manually confirmed by going through all records returned by the lysozyme search. The textual pattern "pKa", however, is actually fairly common throughout the lysozyme record set, and the PREP script successfully eliminated these "pKa" containing records from the search results, whereas the standard Pubmed keyword search is unable to accomplish this. Thus, this test is indicative that with a wellformed regular expression a high degree of specificity and search refinement can be achieved between different words with like character compositions. While no false positives were noted during the manual confirmation of these search results, the potential source of false negatives for this search would be abstracts that discussed Protein Kinase A without mentioning the abbreviation PKA.

The ability of the PREP script to identify elements that cannot be specified as a single word was tested by searching for mutations in the records returned by a search for "hen egg white lysozyme" using the regular expression:

[ARNDCEQGHILKMFPSTWYV]\d+[ARNDCEQGHILKMFPSTWYV]|

$[A-Z][a-z][a-z] \backslash d+[A-Z][a-z][a-z]$

This expression allows for the identification of mutations written out in both the single letter amino acid notation as well as the three-letter notation. The "hen egg white lysozyme" search of Pubmed yielded 1146 records of which 


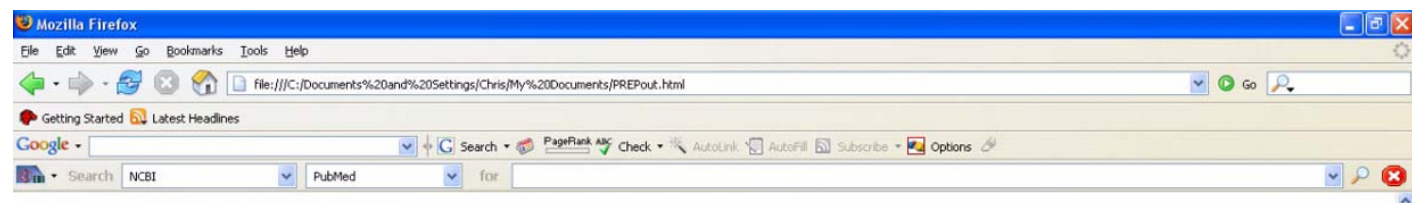

Pattern Match: DFNA10

Eva1 regulates the growth of otic epithelium and interacts with Pax2 during the development of all sensory areas in the inner ear.

Dev Biol 298, $430-41$

Members of the Eyes absent (Eya) gene family are important for auditory system development. While mutations in human EYA4 cause late-onset deafness at the DFNA10 locus, mutations in human EYA1 cause branchio-oto-renal (BOR) syndrome. Inactivation of Eyal in mice causes an early arrest of the inner ear development at the otocyst stage. To better understand the role of Eyal in inner ear development, we analyzed the cellular and molecular basis of the early defect observed in the Eya1 mutant embryos. We report here that Eya1-/. otic epithelium shows reduced cell proliferation from E8.5 and increased cell apoptosis from E9 0 , thus providing insights into the cellular basis of inner ear defect which occurred in the absence of Eyal. Previous studies have suggested that Pax, Eya and Six genes function in a parallel or independent pathway during inner ear development. However, it remains unknown whether Pax genes interact with Eyal or Siz1 during inner ear morphogenesis. To further evaluate whether Pax genes function in the Eya1-Six 1 pathway or whether they interact with Eyal or Six 1 during inner ear morphogenesis, we have analyzed the expression pattern of Eya1. Paxz and Pax8 on adjacent sections of otic epithelium from E8 5 to 9.5 by in situ hybridization and the inner ear gross structures of Pax2. Eyal and Sis 1 compound mutants at E17.5 by latex painfilling Our data strongly suggest that Pax2 interacts with Eyal during inner ear morphogenesis, and this interaction is critical for the development of all sensory areas in the inner ear. Furthermore, otic marker analysis in both Eya1 $\%$ and Pax2-1- embryos indicates that Eyal but not Pax 2 regulates the establishment of regional specification of the otic vesicle Together, these results show that, while Eyal exerts an early function essential for normal growth and patterning of the otic epithelum, it also functionally synergizes with Pax2 during the morphogenesis of all sensory areas of mammalian inner ear.

\section{Pattern Match: DFNB23}

The tip-link antigen, a protein associated with the transduction complex of sensory hair cells, is protocadherin-15.

J Neurosci 26, 7022-34

Sound and acceleration are detected by hair bundles, mechanosensory structures located at the apical pole of hair cells in the inner ear. The different elements of the hair bundle, the stereocilia and a kinocilium, are interconnected by a variety of link types. One of these links, the tip link, connects the top of a shorter stereocilium with the lateral membrane of an adjacent taller stereocilium and may gate the mechanotransducer channel of the hair cell Mass spectrometric and Western blot analyses identify the tip-link antigen, a hitherto unidentified antigen specifically associated with the tip and kinocilial links of 1F/DFNB23 locus. Multiple protocadhern-15 transcripts are shown to be expressed in the mouse inner ear, and these define four major isoform classes, two with entirely novel, previously unidentified cytoplasmic domains. Antibodies to the three cytoplasmic domain-containing isoform classes reveal that each has a different spatiotemporal expression pattem in the developing and mature inner ear. Tw cytoplasmic domains. Antibodies to the three cytoplasmic domain-containing isoform classes reveal that each has a different spatiotemporal expression pattern in the developing and mature inner ear. Tw reappears at the tips of stereocilia as transduction recovers after the removal of calcum chelators. Protocadherin- 15 is therefore associated with the tip-link complex and may be an integral component of the structure and or required for its formation.

\section{Pattern Match: DFNB59}

Mutations in the gene encoding peivakin, a newly identified protein of the afferent auditory pathway, cause DFNB59 auditory neuropathy.

Figure I

A screen shot of the PREP program output for a search for DFN deafness.

PREP identified 62 as matching the above regular expression pattern, and were manually confirmed. Of these 62 matches, 36 (58\%) records contained actual mutations while the remaining $42 \%$ contained false positives, such as the abbreviation for T4 Lysozyme (T4L). In order to lessen the percentage of false positives, the false positives were examined and it became apparent that many of the same false positives occurred in repeated records. Thus a simple filter was created by defining a second regular expression, which explicitly matched the false positives, and prevented them from being recorded in the program output, thereby eliminating these repeating false positives. In this manner, the total number of PREP matches was reduced to 47 , raising the percentage of valid positives up to $77 \%$ and reducing the number of false negatives to $23 \%$. This is indicative that the PREP script can be an effective tool in reducing the search space necessary for manual processing by taking the 1146 initial records and narrowing down the list of possible records to 47 , or $4 \%$ of the original search space. It should be further noted that the PREP script did not miss any records that contained matching patterns within the data set, and that the DFN prefix associated with deafness mutations is less likely to turn up false positives than the more generalized pattern associated with biochemical mutation data. This validation exercise, though, does demonstrate the utility of an application specific filter as a means of reducing false positives where warranted.

\section{Results}

The textual pattern DFN $[A-Z] \backslash d+$ was defined, where [A$Z$ ] could be any letter between $A$ and $Z$ and $\backslash d+$ could be a combination of one or more numeric digits and this pattern used to search through records returned by a PubMed search for the keywords "human ear". The search yielded 61,371 Pubmed records and out of those 117 contained a pattern match. All of the pattern matches corresponded to valid DFN deafness mutations and no false positives were returned. The DFN mutation found in the 117 matching records are summarized in Table 1 . In cases where multiple records discussed a mutation, a representative record is listed in the source field, rather than every record, to limit table length. 


\section{Discussion \& conclusion}

The PREP script was able to process 61,371 Pubmed records displaying the keywords "human ear" and narrow the relevant search space down to 117 articles that contain different DFN deafness mutations. This is slightly less than $0.2 \%$ of the original search space, demonstrating the utility of pattern matching in aiding researchers in obtaining relevant information from the biomedical literature. Furthermore, the lack of false positives among the returned results demonstrates that the accuracy and utility of this approach can be further enhanced when the defined pattern possesses a high degree of specificity. The PREP approach to literature searching would therefore allow researchers to uncover a diversity of information pertaining to deafness mutations in a single search, whereas uncovering the same 45 DFN deafness mutations (Table 1) by standard keyword searches would take considerably more time and effort. However, when utilizing such an approach to literature searching, in addition to false positives, it is important to carefully consider the keywords presented to Pubmed. For example, this "human ear" keyword search failed to uncover the

Table I: Mutations located in the PREP program results

\begin{tabular}{|c|c|c|}
\hline Mutation Name & Mutation Effect & Representative Source \\
\hline DFNAI & Diaphonous gene mutation associated with autosomal dominant non-syndromic hearing loss & 9 \\
\hline DFNAIO & Mutation in EYA4 causes late onset deafness & 10 \\
\hline DFNAII & MYO7A mutation that results in progressive loss of mechanotransduction & II \\
\hline DFNAI 2 & TECTA mutation resulting in hearing impairment & 12 \\
\hline DFNAI 3 & Mutation leading to cochlear conductive loss & 13 \\
\hline DFNAI4 & wolframin mutation cauisng non-syndromic dominant low frequency hearing loss & 14 \\
\hline DFNAI 5 & Mutation in POU4F3 that leads to autosomal dominant non-syndromic hearing loss & 15 \\
\hline DFNAI7 & Mutation in myosin heavy chain IX linked to hearing impairment & 16 \\
\hline DFNA2 & KCNQ4 potassium channel mutation leading to progressive hearing loss & 17 \\
\hline DFNA20 & ACTGI mutation causing autosomal dominant heairng loss & 18 \\
\hline DFNA24 & Caspase 3 mutation associated with autosomal dominant non-syndromic hearing loss & 19 \\
\hline DFNA26 & ACTGI mutation causing autosomal dominant heairng loss & 18 \\
\hline DFNA36 & Mutation in transmembrane cochlear expressed gene I causing progressive deafness & 20 \\
\hline DFNA38 & wolframin mutation cauisng non-syndromic dominant low frequency hearing loss & 14 \\
\hline DFNA39 & Hearing loss associated with Dentinogenesis imperfecta & 21 \\
\hline DFNA4 & MYHI4 mutation leading to autosomal dominant hearing loss & 23 \\
\hline DFNA48 & MYOIA mutation resulting in autosomal dominant hearing loss & 22 \\
\hline DFNA5 & Mutation causing autosomal dominant hearing impairment & 24 \\
\hline DFNA6 & wolframin mutation cauisng non-syndromic dominant low frequency hearing loss & 14 \\
\hline DFNA8 & TECTA mutation resulting in hearing impairment & 12 \\
\hline DFNA9 & Coagulation factor $\mathrm{C}$ homology gene mutations causing sensioneural hearing loss & 25 \\
\hline DFNBI & Connexin 26 mutation leading to non-syndromic hearing loss & 26 \\
\hline DFNBII & Mutation in transmembrane cochlear expressed gene I causing congenital deafness & 20 \\
\hline DFNBI 2 & Cadherin 23 mutation causing prelingual hearing loss & 14 \\
\hline DFNBI3 & Mutations causing autosomal recessive non-syndromic deafness & 27 \\
\hline DFNBI4 & Hearing loss associated with split hand/split foot malformation & 28 \\
\hline DFNBI6 & Stereocilan mutation leading to autsomal recessive non-syndromic deafness & 29 \\
\hline DFNBI7 & FAM3C mutation causing autosomal recessive non-syndromic hearing loss & 30 \\
\hline DFNBI8 & Deafness associated with Usher syndrome IC & 31 \\
\hline DFNB2 & Deafness associated with mutations in myosin VIIA gene & 32 \\
\hline DFNB22 & Otoancorin mutation resulting in autosmal recessive deafness & 33 \\
\hline DFNB23 & Usher Syndrome IF related deafness & 34 \\
\hline DFNB25 & Chromosome 5 mutation that effects sensory mechanotransduction & 35 \\
\hline DFNB28 & TRIOBP mutation resulting in recessive prelingual sensioneural hearing loss & 36 \\
\hline DFNB29 & CLDNI4 mutations resulting in autosomal recessive non-syndromic deafness & 37 \\
\hline DFNB3 & Myol 5 a related non-syndromic deafness & 38 \\
\hline DFNB30 & Mutation in myosin IIIA resulting in progressive hearing loss & 39 \\
\hline DFNB3I & Whirlin mutation resulting in hearing loss & 18 \\
\hline DFNB4 & Mutation in PDS gene causing congenital deafness & 40 \\
\hline DFNB59 & Autosomal recessive auditory neuropathy & 41 \\
\hline DFNB6 & Mutation causing autosomal recessive deafness & 42 \\
\hline DFNB67 & Mutation in THMS causing recessive non-syndromic hearing loss & 43 \\
\hline DFNB7 & Mutation in transmembrane cochlear expressed gene I causing congenital deafness & 20 \\
\hline DFNB8 & TMPRSS3 mutation associated with non-syndromic autosommal recessive hearing loss & 44 \\
\hline DFNB9 & Mutation in otoferlin causing prelingual hearing loss & 45 \\
\hline
\end{tabular}


DFNB35 mutation [8] since it does not appear in an abstract that contains the words "human" and "ear". Potential sources of false negatives among search results include papers that do not utilize the DFN based nomenclature to discuss the mutation or articles that mention the abbreviation in the text, but not the abstract. Based on the validation tests, however, the false negative rate is expected to be low. Even with these limitations, however, the textual pattern based search methodology presented here can be of great value to researchers in the otolaryngological sciences as well as in other biomedical disciplines, since regular expressions can also be created to match other biological patterns, such as DNA or protein sequences, ions, enzyme names, and numerous other possibilities.

\section{Availability \& requirements}

Project Name: PREP: Perl Regular Expressions for PubMed

Project Home Page: http://bioinformatics.org/project/ ?group id=494

Operating Systems: Linux/Unix

Programming Language: Perl

Other Requirements: XML::LibXML Perl Module

License: Perl Artistic License

\section{Competing interests}

The author(s) declare that they have no competing interests.

\section{Authors' contributions}

$\mathrm{CMF}$ is responsible for the study and manuscript in their entirety.

\section{Additional material}

\section{Additional file 1}

The PREP.pl Perl script.

Click here for file

[http://www.biomedcentral.com/content/supplementary/14726947-7-32-S1.pl]

\section{Acknowledgements}

I would like to thank Xiao Meng for her help in testing early versions of the PREP script.

\section{References}

I. Leonard JE, Colombe JB, Levy JL: Finding relevant references to genes and proteins in Medline using a Bayesian approach. Bioinformatics 2002, 18:1515-1522.

2. Yoshida M, Fukuda K, Takagi T: PNAD-CSS: a workbench for constructing a protein name abbreviation dictionary. Bioinformatics 2000, 16:169-175.

3. Andrade MA, Bork P: Automated extraction of information in molecular biology. FEBS Lett 2000, 476:12-17.

4. Wheeler DL, Barrett T, Benson DA, Bryant SH, Canese K, Church DM, DiCuccio M, Edgar R, Federhen S, Helmberg W, Kenton DL, Khovayko O, Lipman DJ, Madden TL, Maglott DR, Ostell J, Pontius JU, Pruitt KD, Schuler GD, Schriml LM, Sequeira E, Sherry ST, Sirotkin K, Starchenko G, Suzek TO, Tatusov R, Tatusova TA, Wagner L, Yaschenko E: Database resources of the National Center for Biotechnology Information. Nucleic Acids Res 2005, 33:D39-D45.

5. Horn F, Lau AL, Cohen FE: Automated extraction of mutation data from the literature: application of MuteXt to $\mathbf{G}$ proteincoupled receptors and nuclear hormone receptors. Bioinformatics 2004, 20:557-568.

6. Frenz CM: Pro Perl Parsing New York: Springer-Verlag; 2005

7. Rebholz-Schuhmann D, Marcel S, Albert S, Tolle R, Casari G, Kirsch $\mathrm{H}$ : Automatic extraction of mutations from Medline and cross-validation with OMIM. Nucleic Acids Res 2004, 32: I35-I42.

8. Ansar M, Din MA, Arshad M, Sohail M, Faiyaz-Ul-Haque M, Haque S, Ahmad W, Leal SM: A novel autosomal recessive non-syndromic deafness locus (DFNB35) maps to 14q24.I-14q24.3 in large consanguineous kindred from Pakistan. Eur J Hum Genet 2003, II:77-80

9. Lalwani AK, Jackler RK, Sweetow RW, Lynch ED, Raventos H, Morrow J, King MC, Leon PE: Further characterization of the DFNAI audiovestibular phenotype. Arch Otolaryngol Head Neck Surg 1998, I 24:699-702.

10. Zou D, Silvius D, Rodrigo-Blomqvist S, Enerback S, Xu PX: Eya I regulates the growth of otic epithelium and interacts with Pax2 during the development of all sensory areas in the inner ear. Dev Biol 2006, 298:430-44I.

II. Bolz H, Bolz SS, Schade G, Kothe C, Mohrmann G, Hess M, Gal A Impaired calmodulin binding of myosin-7A causes autosomal dominant hearing loss (DFNAII). Hum Mutat 2004, 24:274-275

12. Verhoeven K, Van Laer L, Kirschhofer K, Legan PK, Hughes DC, Schatteman I, Verstreken M, Van Hauwe P, Coucke P, Chen A, Smith R, Somers T, Offeciers FE, Van de Heyning P, Richardson GP, Wachtler F, Kimberling WJ, Willems PJ, Govaerts PJ, Van Camp G: Mutations in the human alpha-tectorin gene cause autosomal dominant non-syndromic hearing impairment. Nat Genet 1998, 19:60-62

13. De Leenheer EM, Bosman AJ, Kunst HP, Huygen PL, Cremers CW: Audiological characteristics of some affected members of a Dutch DFNA I 3/COLI I A2 family. Ann Otol Rhinol Laryngol 2004, I I 3:922-929.

14. McHugh RK, Friedman RA: Genetics of hearing loss: Allelism and modifier genes produce a phenotypic continuum. Anat Rec A Discov Mol Cell Evol Biol 2006, 288:370-38I.

15. Hertzano R, Montcouquiol M, Rashi-Elkeles S, Elkon R, Yucel R, Frankel WN, Rechavi G, Moroy T, Friedman TB, Kelley MW, Avraham KB: Transcription profiling of inner ears from Pou4f3(ddl/ddl) identifies Gfil as a target of the Pou4f3 deafness gene. Hum Mol Genet 2004, 13:2/43-2। 53 .

16. Parker LL, Gao J, Zuo J: Absence of hearing loss in a mouse model for DFNAI7 and MYH9-related disease: the use of public gene-targeted ES cell resources. Brain Res 2006, 1091:235-242.

17. Kharkovets T, Dedek K, Maier H, Schweizer M, Khimich D, Nouvian R, Vardanyan V, Leuwer R, Moser T, Jentsch T]: Mice with altered KCNQ4 K+ channels implicate sensory outer hair cells in human progressive deafness. EMBO / 2006, 25:642-652.

18. van Wijk E, Krieger E, Kemperman MH, De Leenheer EM, Huygen PL, Cremers CW, Cremers FP, Kremer H: A mutation in the gamma actin I (ACTGI) gene causes autosomal dominant hearing loss (DFNA20/26). J Med Genet 2003, 40:879-884.

19. Morishita H, Makishima T, Kaneko C, Lee YS, Segil N, Takahashi K, Kuraoka A, Nakagawa T, Nabekura J, Nakayama K, Nakayama KI: Deafness due to degeneration of cochlear neurons in cas- 
pase-3-deficient mice. Biochem Biophys Res Commun 200I, 284: $142-149$.

20. Marcotti W, Erven A, Johnson SL, Steel KP, Kros CJ: Tmcl is necessary for normal functional maturation and survival of inner and outer hair cells in the mouse cochlea. J Physiol 2006, 574:677-698.

21. Xiao S, Yu C, Chou X, Yuan W, Wang Y, Bu L, Fu G, Qian M, Yang J, Shi Y, Hu L, Han B, Wang Z, Huang W, Liu J, Chen Z, Zhao G, Kong $X$ : Dentinogenesis imperfecta I with or without progressive hearing loss is associated with distinct mutations in DSPP. Nat Genet 200I, 27:20I-204.

22. Donaudy F, Ferrara A, Esposito L, Hertzano R, Ben-David O, Bell RE, Melchionda S, Zelante L, Avraham KB, Gasparini P: Multiple mutations of MYOIA, a cochlear-expressed gene, in sensorineural hearing loss. Am J Hum Genet 2003, 72:157|-1577.

23. Donaudy F, SnoeckX R, Pfister M, Zenner HP, Blin N, Di Stazio M, Ferrara A, Lanzara C, Ficarella R, Declau F, Pusch CM, Nurnberg P, Melchionda S, Zelante L, Ballana E, Estivill X, Van Camp G, Gasparini P, Savoia A: Nonmuscle myosin heavy-chain gene MYHI4 is expressed in cochlea and mutated in patients affected by autosomal dominant hearing impairment (DFNA4). Am Hum Genet 2004, 74:770-776.

24. Van Laer L, Pfister M, Thys S, Vrijens K Mueller M, Umans L, Serneels L, Van Nassauw L, Kooy F, Smith RJ, Timmermans JP, Van Leuven F, Van Camp G: Mice lacking Dfna5 show a diverging number of cochlear fourth row outer hair cells. Neurobiol Dis 2005, 19:386-399.

25. Robertson NG, Cremers CW, Huygen PL, lkezono T, Krastins B, Kremer H, Kuo SF, Liberman MC, Merchant SN, Miller CE, Nadol JB, Sarracino DA, Verhagen WI, Morton CC: Cochlin immunostaining of inner ear pathologic deposits and proteomic analysis in DFNA9 deafness and vestibular dysfunction. Hum Mol Genet 2006, I5:107I-1085

26. Palmada M, Schmalisch K, Bohmer C, Schug N, Pfister M, Lang F, Blin $\mathrm{N}$ : Loss of function mutations of the GJB2 gene detected in patients with DFNB I-associated hearing impairment. Neurobiol Dis 2006, 22: I 12-1 I8.

27. Masmoudi S, Charfedine I, Rebeh IB, Rebai A, Tlili A, Ghorbel AM, Belguith $\mathrm{H}$, Petit $\mathrm{C}$, Drira M, Ayadi H: Refined mapping of the autosomal recessive non-syndromic deafness locus DFNB I 3 using eight novel microsatellite markers. Clin Genet 2004, 66:358-364.

28. Fukushima K, Nagai K, Tsukada H, Sugata A, Sugata K, Kasai N, Kibayashi N, Maeda Y, Gunduz M, Nishizaki K: Deletion mapping of split hand/split foot malformation with hearing impairment: a case report. Int J Pediatr Otorhinolaryngol 2003, 67: I I 27-I I32.

29. Verpy E, Masmoudi S, Zwaenepoel I, Leibovici M, Hutchin TP, Del Castillo I, Nouaille S, Blanchard S, Laine S, Popot JL, Moreno F, Mueller RF, Petit C: Mutations in a new gene encoding a protein of the hair bundle cause non-syndromic deafness at the DFNB I 6 locus. Nat Genet 200I, 29:345-349.

30. Pilipenko VV, Reece A, Choo DI, Greinwald JH: Genomic organization and expression analysis of the murine Fam 3c gene. Gene 2004, 335:159-168.

31. Johnson KR, Gagnon LH, Webb LS, Peters LL, Hawes NL, Chang B, Zheng QY: Mouse models of USHIC and DFNBI8: phenotypic and molecular analyses of two new spontaneous mutations of the Ush Ic gene. Hum Mol Genet 2003, I 2:3075-3086.

32. Ernest S, Rauch G], Haffter P, Geisler R, Petit C, Nicolson T: Mariner is defective in myosin VIIA: a zebrafish model for human hereditary deafness. Hum Mol Genet 2000, 9:2 189-2196.

33. Zwaenepoel I, Mustapha M, Leibovici M, Verpy E, Goodyear R, Liu XZ, Nouaille S, Nance WE, Kanaan M, Avraham KB, Tekaia F, Loiselet J, Lathrop M, Richardson G, Petit C: Otoancorin, an inner ear protein restricted to the interface between the apical surface of sensory epithelia and their overlying acellular gels, is defective in autosomal recessive deafness DFNB22. Proc Nat Acad Sci USA 2002, 99:6240-6245.

34. Ahmed ZM, Goodyear R, Riazuddin S, Lagziel A, Legan PK, Behra M, Burgess SM, Lilley KS, Wilcox ER, Riazuddin S, Griffith A], Frolenkov GI, Belyantseva IA, Richardson GP, Friedman TB: The tip-link antigen, a protein associated with the transduction complex of sensory hair cells, is protocadherin-15. J Neurosci 2006, 26:7022-7034

35. Odeh H, Hagiwara N, Skynner M, Mitchem KL, Beyer LA, Allen ND, Brilliant MH, Lebart MC, Dolan DF, Raphael Y, Kohrman DC: Char- acterization of two transgene insertional mutations at pirouette, a mouse deafness locus. Audiol Neurootol 2004, 9:303-3I4.

36. Shahin H, Walsh T, Sobe T, Abu Sa'ed J, Abu Rayan A, Lynch ED, Lee MK, Avraham KB, King MC, Kanaan M: Mutations in a novel isoform of TRIOBP that encodes a filamentous-actin binding protein are responsible for DFNB28 recessive nonsyndromic hearing loss. Am J Hum Genet 2006, 78: I44-I52.

37. Wilcox ER, Burton QL, Naz S, Riazuddin S, Smith TN, Ploplis B, Belyantseva I, Ben-Yosef T, Liburd NA, Morell RJ, Kachar B, Wu DK, Griffith AJ, Riazuddin S, Friedman TB: Mutations in the gene encoding tight junction claudin- 14 cause autosomal recessive deafness DFNB29. Cell 2001, 104:165-172.

38. Kanzaki S, Beyer L, Karolyi IJ, Dolan DF, Fang Q, Probst FJ, Camper SA, Raphael Y: Transgene correction maintains normal cochlear structure and function in 6-month-old Myol 5a mutant mice. Hear Res 2006, 21 4:37-44.

39. Walsh T, Walsh V, Vreugde S, Hertzano R, Shahin H, Haika S, Lee MK, Kanaan M, King MC, Avraham KB: From flies' eyes to our ears: mutations in a human class III myosin cause progressive nonsyndromic hearing loss DFNB30. Proc Natl Acad Sci USA 2002, 99:7518-7523.

40. Albert S, Blons $\mathrm{H}$, Jonard L, Feldmann D, Chauvin P, Loundon N, Sergent-Allaoui A, Houang M, Joannard A, Schmerber S, Delobel B, Leman J, Journel H, Catros H, Dollfus H, Eliot MM, David A, Calais C, Drouin-Garraud V, Obstoy MF, Tran Ba Huy P, Lacombe D, Duriez F, Francannet C, Bitoun P, Petit C, Garabedian EN, Couderc R, Marlin $S$, Denoyelle F: SLC26A4 gene is frequently involved in nonsyndromic hearing impairment with enlarged vestibular aqueduct in Caucasian populations. Eur J Hum Genet 2006, 14:773-779.

4l. Delmaghani S, del Castillo FJ, Michel V, Leibovici M, Aghaie A, Ron U, Van Laer L, Ben-Tal N, Van Camp G, Weil D, Langa F, Lathrop M, Avan P, Petit C: Mutations in the gene encoding pejvakin, a newly identified protein of the afferent auditory pathway, cause DFNB59 auditory neuropathy. Nat Genet 2006, 38:770-778.

42. Cho KI, Lee JW, Kim KS, Lee EJ, Suh JG, Lee HJ, Kim HT, Hong SH, Chung WH, Chang KT, Hyun BH, Oh YS, Ryoo ZY: Fine mapping of the circling ( $\mathrm{cir}$ ) gene on the distal portion of mouse chromosome 9. Comp Med 2003, 53:642-648.

43. Shabbir MI, Ahmed ZM, Khan SY, Riazuddin S, Waryah AM, Khan SN, Camps RD, Ghosh M, Kabra M, Belyantseva IA, Friedman TB, Riazud$\operatorname{din} \mathrm{S}$ : Mutations of human TMHS cause recessively inherited non-syndromic hearing loss. J Med Genet 2006, 43:634-640.

44. Guipponi M, Vuagniaux G, Wattenhofer M, Shibuya K, Vazquez M, Dougherty L, Scamuffa N, Guida E, Okui M, Rossier C, Hancock M, Buchet K, Reymond A, Hummler E, Marzella PL, Kudoh J, Shimizu N, Scott HS, Antonarakis SE, Rossier BC: The transmembrane serine protease (TMPRSS3) mutated in deafness DFNB8/10 activates the epithelial sodium channel (ENaC) in vitro. Hum Mol Genet 2002, I I:2829-2836.

45. Rodriguez-Ballesteros M, del Castillo FJ, Martin Y, Moreno-Pelayo MA, Morera C, Prieto F, Marco J, Morant A, Gallo-Teran J, MoralesAngulo C, Navas C, Trinidad G, Tapia MC, Moreno F, Del Castillo I: Auditory neuropathy in patients carrying mutations in the otoferlin gene (OTOF). Hum Mutat 2003, 22:45 I-456.

\section{Pre-publication history}

The pre-publication history for this paper can be accessed here:

http://www.biomedcentral.com/1472-6947/7/32/prepub 